\title{
L2/L3 acquisition of the English indefinite article
}

\author{
Asma Al-hawi ${ }^{1}$, Sviatlana Karpava ${ }^{2}$ \\ ${ }^{1}$ Division of Education \& Linguistics, University of Central Lancashire, Cyprus/UK \\ ${ }^{2}$ Department of English studies, University of Cyprus, Cyprus \\ https://doi.org/10.36505/ExLing-2019/10/0003/000365
}

\begin{abstract}
This study aimed to explore the L2/L3 acquisition of the English indefinite article by L1 speakers of Palestinian/Jordanian-Arabic (PJ/A) and Cypriot-Greek (CG) in Jordan and Cyprus. Four groups were recruited: an English control group, two L2 groups, whose L1s are PJ/A or CG, and an L3 group, whose L1 is PJ/A with L2 CG. A forcedchoice-elicitation task was used for data collection. Data analysis revealed that the L2 PJ and L2 CG participants had both negative and positive/negative transfer from their L1 into L2, respectively. The results of the L3 participants revealed that their performance was similar to the L2 CG group. Overall, the results of the L2/L3 groups lend partial support to the Fluctuation Hypothesis $(\mathrm{FH})$.
\end{abstract}

Key words: L2/L3 acquisition, indefinite article, transfer

\section{Cross-linguistic differences among English, PJ/A and CG}

In $\mathrm{PJ} / \mathrm{A}$, there is no morphological realization of the indefinite article (Abudalbuh 2016). Therefore, indefinite NPs are always bare. In English and CG, the indefinite article exists. Yet, in Greek singular bare NPs are sanctioned when they are the objects of (i) light verbs or (ii) verbs of accomplishment (Marinis 2003), see examples (1) and (2):

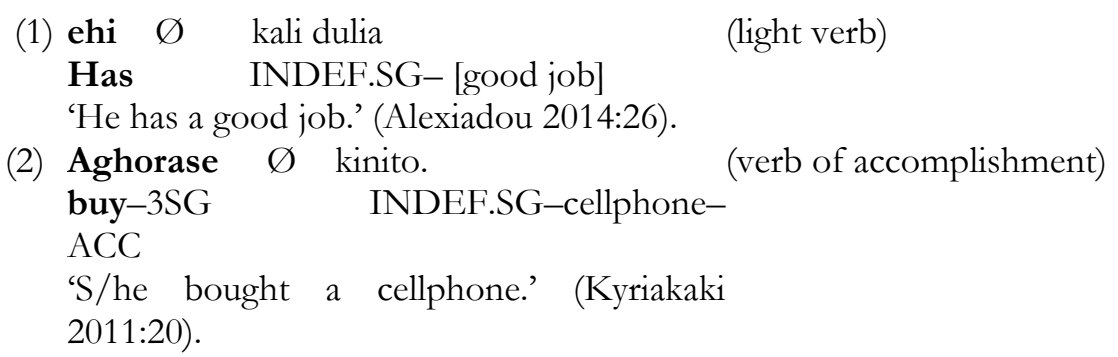

\section{Hypotheses and predictions}

The data of the study was analysed in light of the predictions of the $\mathrm{FH}$ by Ionin et al. (2008). The first prediction is associated with article languages such as CG and; therefore, assumes that transfer overrides fluctuation. Thus, it is expected that the L2 CG participants would not find it difficult to supply $a(n)$ in the target contexts even when they are at lower English proficiency levels. The

ExLing 2019: Proceedings of $10^{\text {th }}$ International Conference of Experimental Linguistics, 25-27 September 2019, Lisbon, Portugal 


\section{A. Al-hawi, S. Karpava}

second prediction is related to article-less languages like $\mathrm{PJ} / \mathrm{A}$. In that case fluctuation overrides transfer (ibid). Accordingly, the L2 PJ participants are expected to fluctuate between the definiteness setting and the specificity setting of the article choice parameter until they had enough input to help them fix the parameters associated with the English indefinite article.

Thus, the primary goal of this study is to examine the L2/L3 acquisition of the English indefinite article by seeking answers to the following research questions (RQs):

RQ1: Is there any L2/L3 English proficiency effect on the performance of each of the L2/L3 groups?

RQ2: Can the patterns of acquisition of the experimental groups be explained in light of the predictions of the FH (Ionin et al., 2008)?

\section{Participants and data collection methods}

Four groups of participants were recruited in Cyprus and Jordan: English native speakers, control group ( $\mathrm{n}=27)$; two L2 groups: L2 PJ ( $\mathrm{n}=91)$ and L2 CG $(n=93)$ and an L3 PJ-CG-E group $(n=52)$. Data was collected by means of a written FCET and a questionnaire. The questionnaire aimed to collect some information about the participants. One piece of information that this study is interested in is related to the L2/L3 English proficiency levels of the participants. Accordingly, the participants of the experimental groups were classified into five English proficiency levels. The English levels were as follows: low intermediate (LI), intermediate (Inter), upper intermediate (UI), advanced (Adv) and upper advanced (UA).

Following Ionin, Ko and Wexler (2004), two contexts were examined in the FCET and each context included six sentences. In each sentence, the participants were provided with three options: (the, $a / n, \varnothing)$. The first context examined NPs with the features [-definite, + specific], see example (3):

(3) I attended a workshop in statistics. It was boring.

The second context examined NPs with the features [-definite, specific], see example (4):

(4) My aunt bought a house, but I don't know where exactly. 


\section{Results and discussion}

The results showed that English proficiency had an effect on the performance of the L2/L3 groups. In comparison with the EN group, none of the experimental groups was native-like in supplying $a(n)$, see Table 1 .

Table 1. Elicitation test results per English proficiency level.

\begin{tabular}{|c|c|c|c|c|c|c|c|}
\hline \multirow[t]{2}{*}{ Groups } & \multirow{2}{*}{$\begin{array}{l}\text { English } \\
\text { proficiency }\end{array}$} & \multicolumn{3}{|c|}{ [+specific] } & \multicolumn{3}{|c|}{ [-specific] } \\
\hline & & $a(n)$ & the & zero & $a(n)$ & the & zero \\
\hline \multirow[t]{6}{*}{ L2 PJ } & LI & $35.2 \%$ & $24.1 \%$ & $40.7 \%$ & $57.4 \%$ & $22.2 \%$ & $20.4 \%$ \\
\hline & Inter & $59.4 \%$ & $19.8 \%$ & $20.8 \%$ & $71.9 \%$ & $12.5 \%$ & $15.6 \%$ \\
\hline & UI & $65.3 \%$ & $18.0 \%$ & $16.7 \%$ & $88.0 \%$ & $3.3 \%$ & $8.7 \%$ \\
\hline & Adv & $74.7 \%$ & $17.3 \%$ & $8.0 \%$ & $86.7 \%$ & $8.6 \%$ & $4.7 \%$ \\
\hline & UA & $83.3 \%$ & $8.4 \%$ & $8.3 \%$ & $92.7 \%$ & $5.2 \%$ & $2.1 \%$ \\
\hline & Total & $67.0 \%$ & $17.1 \%$ & $15.9 \%$ & $82.6 \%$ & $8.6 \%$ & $8.8 \%$ \\
\hline \multirow[t]{6}{*}{ L2 CG } & LI & $47.9 \%$ & $25.0 \%$ & $27.1 \%$ & $52.0 \%$ & $24.0 \%$ & $24.0 \%$ \\
\hline & Inter & $72.6 \%$ & $14.3 \%$ & $13.1 \%$ & $88.1 \%$ & $4.8 \%$ & $7.1 \%$ \\
\hline & $\overline{\mathrm{UI}}$ & $82.6 \%$ & $9.1 \%$ & $8.3 \%$ & $89.4 \%$ & $4.5 \%$ & $6.1 \%$ \\
\hline & Adv & $93.9 \%$ & $2.3 \%$ & $3.8 \%$ & $95.5 \%$ & $0.0 \%$ & $4.5 \%$ \\
\hline & UA & $93.9 \%$ & $3.5 \%$ & $2.6 \%$ & $93.9 \%$ & $0.0 \%$ & $6.1 \%$ \\
\hline & Total & $80.1 \%$ & $9.9 \%$ & $10.0 \%$ & $85.1 \%$ & $5.9 \%$ & $9.0 \%$ \\
\hline \multirow{6}{*}{$\begin{array}{l}\text { L3 PJ } \\
\text { CG-E }\end{array}$} & $\mathrm{LI}$ & $46.2 \%$ & $28.2 \%$ & $25.6 \%$ & $56.5 \%$ & $25.6 \%$ & $17.9 \%$ \\
\hline & Inter & $57.4 \%$ & $27.8 \%$ & $14.8 \%$ & $63.0 \%$ & $25.9 \%$ & $11.1 \%$ \\
\hline & UI & $75.0 \%$ & $15.3 \%$ & $9.7 \%$ & $80.6 \%$ & $12.5 \%$ & $6.9 \%$ \\
\hline & Adv & $90.0 \%$ & $8.3 \%$ & $1.7 \%$ & $95.0 \%$ & $3.3 \%$ & $1.7 \%$ \\
\hline & UA & $93.8 \%$ & $4.1 \%$ & $2.1 \%$ & $93.7 \%$ & $2.1 \%$ & $4.2 \%$ \\
\hline & Total & $70.5 \%$ & $17.6 \%$ & $11.9 \%$ & $76.3 \%$ & $14.7 \%$ & $9.0 \%$ \\
\hline EN & Native & $97.5 \%$ & $0.6 \%$ & $1.9 \%$ & $98.2 \%$ & $0.0 \%$ & $1.8 \%$ \\
\hline
\end{tabular}

A Pearson correlation coefficient was computed to evaluate the relations between the L2/L3 group's proficiency level and the participants' article use in each context. As an answer to RQ1, the results of the L2 PJ group indicate a positive correlation between the two variables in context $\mathrm{E}(\mathrm{r}=.571, \mathrm{p}=.000)$ and in context $\mathrm{F}(\mathrm{r}=.423, \mathrm{p}=.000)$. For the L2 CG group, it was also found a positive correlation between the two variables in context $\mathrm{E}(\mathrm{r}=.661, \mathrm{p}=.000)$ and context $\mathrm{F}(\mathrm{r}=.561, \mathrm{p}=.000)$. The results of L3 PJ-CG-E group indicate that there was a positive correlation between the two variables in context $\mathrm{E}(\mathrm{r}=$ $.706, \mathrm{p}=.000)$ and in context $\mathrm{F}(\mathrm{r}=.571, \mathrm{p}=.000)$.

Regarding the L2 PJ group's target-like performance, the pair wise comparisons show that the percentages of the participants from the LI $(\mathrm{p}=.022)$, Inter $(\mathrm{p}=.029), \mathrm{UI}(\mathrm{p}=.000)$ and $\mathrm{Adv}(\mathrm{p}=.047)$ levels in the [-specific] context were significantly higher than their percentages in the [+specific] 
context. Consistent with the predictions of the $\mathrm{FH}$, the pairwise t-tests of the substitution errors reveal that the percentages of the L2 PJ participants' in providing the in the [+specific] context were significantly higher than the percentages in [-specific] context $(\mathrm{p}=.010)$. The specificity effect decreased the more advanced the participants were in English. The pair wise comparisons of the L2 CG group and the L3 groups, on the other hand, showed that neither the use of $a(n)$ nor the in the [+specific] context were significantly different from the $[-$ specific $]$ context $(\mathrm{p}>0.05)$.

\section{Conclusion}

Overall, it was found that the L2/L3 participants of higher proficiency in English were more target-like than the participants of lower English proficiency levels. Yet, the results reveal that the L2 PJ participants seemed to have more difficulty in supplying $a(n)$ in the [+specific] context than [-specific] context as their L1 lacks the indefinite article. In contrast, the L2 English proficiency had an effect on the performance of the L2 CG participants. This means that the L2 CG participants did not seem to benefit from the presence of the indefinite article in their L1 at the lower English proficiency levels. On the other hand, the L3 advanced and upper advanced participants benefited from their L2 Greek in supplying $a(n)$ properly. They were even more target-like than the L2 PJ group of the comparable English proficiency levels. The results of the L2 PJ group supported the $\mathrm{FH}$ as the participants showed evidence of fluctuation and proficiency effect. Yet, the results of the L2 CG and the L3 group were not completely in line with the FH. More specifically, the results of the L2 CG participants showed evidence of a proficiency effect though there was no specificity effect.

\section{References}

Abudalbuh, M. 2016. The acquisition of English articles by Arabic L2-English learners: A semantic approach. Arab World English Journal 7, 104-117.

Alexiadou, A. 2014. Multiple Determiners and the Structure of DPs. Amsterdam, John Benjamins Publishing Company.

Ionin, T., Ko, H., Wexler, K. 2004. Article semantics in L2 acquisition: The role of specificity. Language Acquisition 12, 3-69.

Ionin, T., Zubizarreta, M., Bautista-Maldonado, S. 2008. Sources of linguistic knowledge in the second language acquisition of English articles. Lingua 118, 554576.

Kyriakaki, M. 2011. DETs in the functional syntax of Greek nominals. Journal of Greek Linguistics 11, 293-29.

Mackey, A., Gass, S. 2005. Second Language Research: Methodology and Design. Mahwah, New Jersey, Lawrence Erlbaum Associates, Inc.

Marinis, T. 2003. Acquisition of the DP in Modern Greek. Amsterdam, Philadelphia, John Benjamins Publishing Company. 